\title{
Seroprevalencia de SARS-COV-2 en una población rural del Ecuador
}

\author{
Larco Danny[1]. \\ 1. Hospital Saludesa, Laboratorio de Microbiología y Biología Molecular, Santo Domingo, Ecuador.
}

Doi: $\underline{\text { https://doi.org/10.23936/pfr.v6i2.207 }}$

RURAL FAMILY PRACTICE | Vol.6 | No.2 | Julio 2021 | Recibido: 13/06/2021 | Aprobado: 29/07/2021
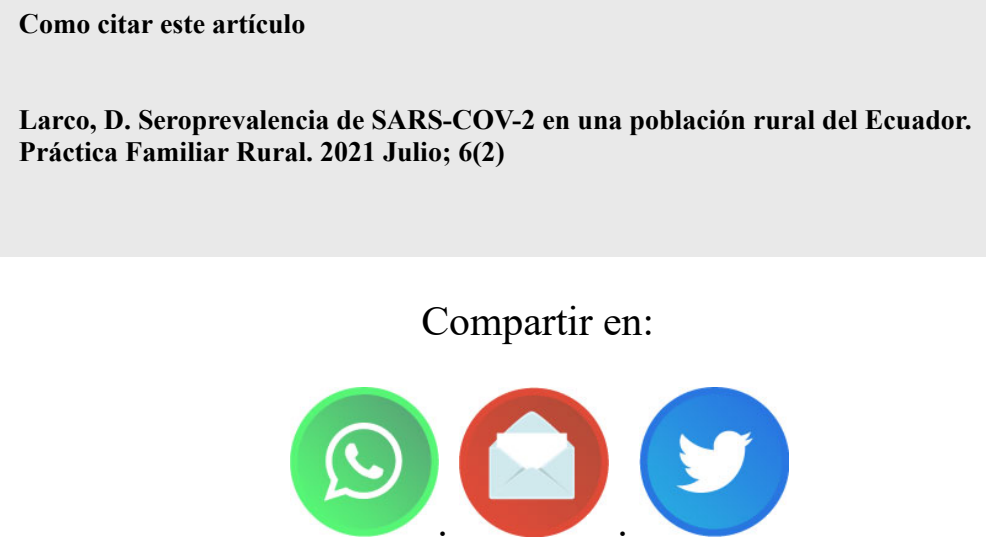

\section{Resumen}

El presente estudio busca determinar los anticuerpos totales tipo $\operatorname{IgG}$, IgM e $\operatorname{IgA}$ frente a SARS COV-2 en una población de la sierra ecuatoriana. El universo muestral lo comprenden 318 personas adultas, 187 hombres y 131 mujeres. El porcentaje de positividad fue del $42.5 \%$. Previo a la toma muestral se realizó una encuesta sobre la sintomatología, pruebas diagnósticas y vacunación de SARS COV-2. Se encontró correlación de resultados positivos para nuestro test con participantes que presentaron sintomatología de infección de SARS COV-2 confirmada por PCR $(89.7$ \%), también correlación entre personas que aseguraron no haber tenido síntomas de infección por SARS COV-2 con resultados del test negativos $(75.6 \%)$. Hubo un escaso número de resultados catalogados como falsos negativos $(2.8 \%)$. Además resultados de personas que aseguraron nunca haber tenido síntomas de infección por SARS COV-2 y obtuvieron resultados positivos en los test de anticuerpos (14.7\%) que vendrían a ser considerados como portadores asintomáticos.

Palabras clave: SARS COV-2, anticuerpos, seroprevalencia, vacuna, sintomatología, ELISA. 


\title{
Seroprevalence of SARS-COV-2 in a rural population of Ecuador
}

\begin{abstract}
The present study seeks to determine the total IgG, IgM and IgA antibodies against SARS COV-2 in a rural population of the Ecuadorian highlands. The population was 318 adults, 187 men and 131 women with positivity of $42.5 \%$. Surveys were conducted in which information was requested regarding the presence or absence of SARS COV-2 symptoms, whether additional laboratory diagnostic tests had been performed, and regarding their vaccination status. There is a correlation of $89.7 \%$ of positive results with patients who presented pictures or symptoms of SARS COV-2. Likewise, in patients who claimed not to have presented symptoms of SARS COV-2 infection with negative test results, the correlation is $75.6 \%$. The results cataloged as false negatives add up to $2.8 \%$ and the cases that claimed to have never had symptoms of SARS COV-2 infection and obtained positive results in the antibody test represent $14.7 \%$ that would be considered as asymptomatic carriers.
\end{abstract}

Keywords: SARS COV-2, antibodies, seroprevalence, vaccine, symptoms, ELISA.

\section{Introducción}

La pandemia causada por el SARS COV-2 ha sido un acontecimiento que ha desencadenado una serie de cambios tanto sociales, culturales y científicos que ha llevado a la humanidad a superar los límites de su conocimiento. En el ámbito de la salud ha generado un hito en cuanto a los métodos para su diagnóstico, así como para las alternativas para su tratamiento.

Todo esto es causado muchas de las veces por la dificultad para poder identificar casos asintomáticos de SARS COV-2, esto ha llevado a estimar la seroprevalencia en la población, tanto sintomática como asintomática. La medición de anticuerpos (IgG, IgM, IgA) puede ayudar a precisar la epidemiologia de SARS COV-2 de forma más precisa.

Un estudio de meta-análisis de 47 estudios de 23 países de seroprevalencia de SARS COV-2 a nivel mundial demuestra infecciones previas de poblaciones en el rango de $0.37 \%$ hasta $22.1 \% \%$ con un promedio de $3.38 \%$ (1) Específicamente en América del Sur, el estudio encontró una seroprevalencia de 0.95-1.94\%

En el caso del Ecuador un estudio de seroprevalencia de la Universidad de Cuenca realizado en el año 2020, en el cantón Cuenca con 2457 participantes, identifico un porcentaje de positividad del 10\%. (2) Otro estudio esta vez a 128 personas todas ellas personal de salud que trabajan en la ciudad de Jipijapa, provincia de Manabí en la costa ecuatoriana obtuvo una seroprevalencia para SARS COV-2 del $22.65 \%$, presentándose más en hombres $(57.7 \%)$ y entre 36 y 64 años $(52.5 \%)$. (3)

Los estudios de seroprevalencia, que buscan la presencia de IgG e IgM de COVID tienen muchos limitantes, empezando con la sensibilidad y especificidad baja de muchas pruebas de seroprevalencia (4).

Para este estudio, usamos una prueba de inmunoensayo enzimático para anticuerpos totales $\operatorname{IgA} \operatorname{IgM}$ e $\operatorname{IgG}$ de SARS COV-2 del laboratorio IMMY (Oklahoma, USA) con una sensibilidad del 92\% y una especificidad del 100\%, Sin embargo, la prueba no es aprobada para diagnosticar infección aguda, ni para dejar de usar equipo de protección personal.

El propósito de este estudio fue determinar la seroprevalencia del grupo muestral de trabajadores del Municipio de Pujilí frente a la infección por SARS COV-2, en un momento en que la vacunación alcanzaba 
menos del $2 \%$ de la población nacional.

\section{Métodos}

El siguiente es un estudio descriptivo transversal cualitativo que valora la seroprevalencia de SARS COV-2 en un periodo de tiempo determinado, en una población determinada. El universo muestral lo constituyen el personal que trabaja en el Municipio de la ciudad de Pujilí, ciudad de la sierra ecuatoriana en la provincia de Cotopaxi, Ecuador. La variable a analizar es la presencia o ausencia de anticuerpos totales tipo IgG, IgM o IgA frente a SARS COV-2.

\section{Reclutamiento de participantes}

El estudio se realizó en el primer semestre de 2021, las muestras del estudio de forma gratuita, luego de hacerles firmar las hojas de consentimiento. La muestra utilizada fue por conveniencia mutua. Los participantes seleccionados para el estudio lo conforman los empleados de nómina que trabajan en el Municipio del cantón Pujilí de la provincia de Cotopaxi, Ecuador. La ciudad de Pujilí es una ciudad de la sierra ecuatoriana ubicada a $2960 \mathrm{~m}$ sobre el nivel del mar, en la cadena occidental de la Cordillera de los Andes. Tiene un clima frío a templado andino y posee aproximadamente 22100 habitantes. Los principales grupos étnicos son mestizos e indígenas y la principal actividad económica de la zona es la agricultura.

\section{Recolección y transporte de las muestras}

Se obtuvieron para el procesamiento $10 \mathrm{cc}$ de sangre venosa mediante la técnica de venopunción con sistema de tubos al vacío. Luego las muestras fueron rotuladas e identificadas en frente de cada persona del estudio y fueron centrifugadas y almacenadas en refrigeración en coolers con hielo monitoreados por termómetros digitales hasta llegar a las instalaciones del laboratorio en donde fueron almacenadas en refrigeradores hasta su procesamiento posterior. Hay que tomar en cuenta que se manejó una estricta cadena de frío durante todo el transporte, así como en el almacenamiento definitivo.

\section{Procesamiento de las muestras}

La prueba de anticuerpos totales para SARS COV-2 es un inmunoensayo enzimático tipo "sándwich" que usa, antígenos recombinantes SARS COV-2 como agente de detección adheridos a los micropocillos. Los micropocillos son analizados en un lector de microelisa a una doble longitud de onda (450 nm y $630 \mathrm{~nm}$ ). Luego los OD de las muestras son comparados con el OD del control Cut Off y se obtiene las unidades EIA que nos dan una referencia sobre positivo o negativo. A la vez se corren controles Positivo y Negativo como control en duplicado para validar la corrida.

Este ensayo detecta anticuerpos totales, es decir todos los subtipos de inmunoglobulinas, por lo tanto no es posible la diferenciación entre estos. Los anticuerpos detectables pueden aparecer entre 5 a 17 días desde la aparición de síntomas siendo muy útiles para identificar la prevalencia o exposición al patógeno en ciertas poblaciones y condiciones. La presencia de anticuerpos totales detectables en sangre post infección no está bien caracterizada por lo que la permanencia de los anticuerpos en sangre periférica puede variar ampliamente, así como algunos individuos pueden tener cantidades detectables del virus en sangre periférica semanas luego de la seroconversión.

\section{Disposición final}

Las muestras fueron almacenadas en congeladores a $-20^{\circ} \mathrm{C}$ en las instalaciones del Hospital Saludesa, para poder proteger la identidad de los participantes y de ser necesario ser reanalizadas. Las hojas con los consentimientos, las listas y los resultados se encuentran resguardados en el laboratorio de Microbiología del Hospital con acceso solo a personal relacionado con la investigación. Así aseguramos la confidencialidad de los resultados obtenidos.

De igual manera se envió la lista de resultados a la trabajadora social y a al médico ocupacional del 
Municipio de Pujilí para que ellas sean las encargadas de notificar a cada trabajador su estado inmunológico frente al SARS COV-2 y solventar cualquier duda que puedan tener.

\begin{tabular}{|c|c|c|c|}
\hline & & \multicolumn{2}{|c|}{ TOTAL } \\
\hline & & $\#$ & $\%$ \\
\hline \multirow{3}{*}{ 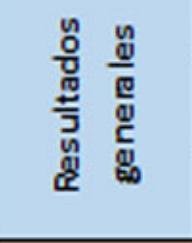 } & Prueb as realizadas & 318 & 100,0 \\
\hline & Re sultad os positivos & 135 & 42,5 \\
\hline & Re sultad os negativos & 183 & 57,5 \\
\hline \multirow{2}{*}{$\begin{array}{l}\frac{9}{11} \\
\frac{2}{9} \\
0\end{array}$} & Hombres & 187 & 58,8 \\
\hline & Mujeres & 131 & 41,2 \\
\hline \multirow{4}{*}{$\begin{array}{l}\text { D } \\
\text { 要 }\end{array}$} & menores de 30 años & 51 & 16,0 \\
\hline & 30-40 años & 118 & 37,1 \\
\hline & $41-50$ años & 81 & 25,5 \\
\hline & mayores de 50 años & 68 & 21,4 \\
\hline \multirow{3}{*}{ 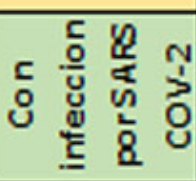 } & Total & 87 & 27,4 \\
\hline & Re sultado positivo & 78 & 24,5 \\
\hline & Re sultad o negativo & 9 & 2,8 \\
\hline \multirow{3}{*}{ 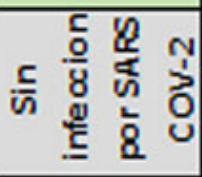 } & Total & 231 & 72,6 \\
\hline & Re sultad o positivo & 56 & 17,6 \\
\hline & Re sultado negativo & 175 & 55,0 \\
\hline \multirow{3}{*}{$\begin{array}{l}\mathrm{g} \\
\text { J } \\
\text { s }\end{array}$} & Total & 29 & 9,1 \\
\hline & Re sultad o positivo & 20 & 6,3 \\
\hline & Re sultad o negativo & 9 & 2,8 \\
\hline
\end{tabular}

Tabla 1. Resultados y pocentajes obtenidos en el muestreo de anticuerpos totales frente a SARS COV-2.

\section{Resultados}

Fueron procesadas 318 muestras de las cuales, 135 dieron resultados positivos $(42.5 \%)$ y 183 dieron resultados negativos $(57.5 \%)$. El $58.5 \%$ de las muestras procesadas eran de hombres. El grupo etario más frecuente es el de 30 a 40 años con un $37.1 \%$ y el menos frecuente eran las personas menores de 30 años con un $16.0 \%$.

87 personas (27.4\%) aseguraron ya haber padecido infección por SARS COV-2, de las cuales 9 (2.8\%) dieron un resultado negativo para el test. 231 personas (72.6\%) aseguraron nunca haber padecido infección por SARS COV-2, de las cuales $56(17.6 \%)$ obtuvieron un resultado positivo para el test. Solo 29 personas (9.1\%) habían recibido al menos una dosis del esquema de vacunación del Ministerio de Salud Pública.

Como otros hallazgos importantes podemos destacar que de la encuesta realizada a los sujetos del estudio 87 personas (27.4\%) aseguraron que tuvieron en algún momento infección por SARS COV-2 (en su mayoría confirmada con métodos de PCR y en otros casos con pruebas rápidas).

- 78 de ellas (22.4\%) resultaron positivo al test corroborando la presencia de anticuerpos.

- 9 personas $(2.8 \%)$ dieron el resultado negativo, 4 personas con PCR positiva desde hace más de un año, 2 de ellas tuvieron una prueba PCR positiva hace menos de 2 semanas. Esto explicaría la 
ausencia de anticuerpos totales y por ende el test negativo. Tres de ellas tuvieron los sintomas entre 12 y 24 semanas, pero no se realizaron una prueba de PCR para confirmar el hallazgo de SARS COV-2 por lo que no se consideran como resultados falsos negativos.

Por otra parte 231 personas (72.6\%) aseguraron que nunca tuvieron síntomas de infección por COVID.

- 175 de ellas (55.0\%) obtuvieron resultados negativos corroborando la ausencia de anticuerpos frente al SARS COV-2.

- 56 personas (17.6\%) en cambio dieron un resultado positivo de anticuerpos a pesar de haber indicado en la encuesta que nunca tuvieron sintomatología de SARS COV-2 lo que vendría a considerarse como pacientes portadores asintomáticos.

Veinte y nueva (29) personas participantes, aseguraron haber recibido la vacuna para SARS COV-2 (9.1\%). De ellos 20 personas obtuvieron un resultado positivo (6.3\%) mientras que 9 personas dieron un resultado negativo $(2.8 \%)$, es muy importante aclarar que solo 2 personas del total habían recibido el esquema de vacunación completo del Ministerio de Salud Pública, ya que la mayoría solo había recibido una dosis de vacuna, lo que podría explicar la baja tasa de casos positivos en este grupo.

\section{Discusión}

En la actualidad hay gran variedad de pruebas para la detección de anticuerpos de este virus, las primeras en aparecer se encargaban de detectar anticuerpos tipo inmunoglobulina $\mathrm{G}$ e inmunoglobulina $\mathrm{M}$ en sangre periférica primero como pruebas inmunocromatográficas, para luego avanzar a métodos más avanzados como inmunofluorescencia, ELISA o quimioluminiscencia. Surgía la necesidad de detectar a pacientes en el momento del cuadro clínico y a posibles portadores asintomáticos, por lo que las pruebas de anticuerpos fueron inútiles debido a que se necesitaban semanas para que los anticuerpos en sangre periférica sean detectables. Por esto surgieron pruebas más avanzadas como es la detección de ARN viral mediante reacción en cadena de la polimerasa (PCR) y después pruebas de detección de antígeno de SARS COV-2.

En la actualidad se han desarrollado también pruebas de anticuerpos dirigidas contra la proteína Spike y contra los llamados anticuerpos neutralizantes dirigidos a los sitios de unión del virus en la célula. Con esta variedad de pruebas en la actualidad es posible saber con cierto grado de probabilidad el perfil epidemiológico de cada persona frente al SARS COV-2.

Hay que recalcar que las pruebas de anticuerpos totales como la que usamos en este estudio tiene como objetivos, el diagnóstico de infección por SARS COV-2 en pacientes sin síntomas con PCR negativa, determinar casos de infección previa por SARS COV-2 en individuos asintomáticos, evaluar la capacidad de generación de anticuerpos post vacunación y para determinar la seroprevalencia (población con respuesta inmune) frente a la infección de SARS COV-2 en poblaciones limitadas. Este estudio refleja el grado de transmisión comunitaria de SARS COV-2, en un momento en que la cobertura de la vacunación era insuficiente.

Hay que tomar en cuenta varios puntos epidemiológicos respecto a las pruebas de anticuerpos que deben ser considerados.

- La precisión de dichas pruebas diagnósticas varí ampliamente, por lo que al momento de elegir un método para realizar dichos análisis hay que considerar muchas variables teniendo en cuenta la posibilidad de encontrar falsos positivos y falsos negativos.

- Las pruebas de anticuerpos por si mismas no son una prueba primaria para el diagnóstico de infección activa por SARS COV-2

- Aunque no hay muchas informaciones al respecto se considera que las pruebas de anticuerpos detectan infección previa por SARS COV-2 a partir de 15 días después del inicio de los síntomas. Por lo que se entiende que mientras más tiempo haya transcurrido desde el inicio de los síntomas la sensibilidad de las pruebas de anticuerpos aumenta. 
- No se conoce la duración exacta de la respuesta inmune, pero se describen casos de pacientes tanto con reinfecciones después de largos periodos de tiempo, así como presencia de anticuerpos incuantificables en pacientes que tuvieron enfermedad de SAR COV-2 hace más de un año.

Muchas de las pruebas comerciales carecen de pruebas de validación y evaluación o en muchos casos la evidencia, no están disponibles al público. Hay que recalcar que los porcentajes de positividad de la muestra superan el 35\%, un porcentaje superior a lo establecido por los organismos oficiales., lo que nos manifiesta el alto grado de transmisibilidad que hubo en esta población, así como en la región interandina. Creemos debido a las limitaciones económicas y culturales en las que convive esta población.

Existe una buena correlación de resultados positivos con pacientes que presentaron cuadros o sintomatología de SARS COV-2 (90.0\%). Así como una regular correlación entre personas que aseguraron no haber tenido síntomas de infección por SARS COV-2 con resultados del test negativos (75.8\%).

Tenemos 9 personas $(2.8 \%)$ que serían catalogadas como falsos negativos debido a que tuvieron resultados de PCR positivos y nuestro test dio negativo para presencia de anticuerpos esto puede deberse a la sensibilidad de la prueba.

Un dato importante son las 56 personas (17.6\%) que aseguraron nunca tener síntomas de infección por SARS COV-2 y obtuvieron resultados positivos en los test de anticuerpos. A este grupo podríamos considerarlo como portadores asintomáticos, es decir que tuvieron la infección por SARS COV-2 pero nunca desarrollaron síntomas de la misma.

No pudimos obtener valores predictivos positivos ni negativos del test empleado, así como tampoco pudimos evaluar el nivel de especificidad y sensibilidad de la prueba debido a que no pudimos comparar los resultados obtenidos con una prueba "gold estándar".

Los resultados de seroprevalencia, fueron superiores a otros estudios realizados en Ecuador, y muestra marcadas diferencias con estudios en países de Asia Europa o Estados Unidos, esto debido al avance de la enfermedad en el tercer mundo y a la débil campaña de vacunación implementada en los países Latinoamericanos.

También hay que considerar que hay estudios actualmente que indican que hay ciertas personas que no presentan anticuerpos detectables en sangre luego de la infección por SARS COV-2 ni después del esquema completo de vacunación por lo que los resultados deben ser manejados e interpretados muy claramente dentro del marco epidemiológico local, y no como un resultado estricto y definitivo.

\section{Conclusión}

En conclusión, los resultados obtenidos muestran un alto porcentaje de presencia de títulos de anticuerpos en este grupo poblacional (42.5\%), en un país donde al momento del estudio la vacunación de la población, no llegaba ni al $2 \%$ de la población general. Se encontró además, una muy buena correlación de resultados positivos y negativos de la prueba con la presencia de sintomatología de SARS COV-2 en las personas participantes en el estudio.

\section{Referencias}

1. Rostami A, Sepidarkish M, Leeflanf M, et al. (2020). SARS-CoV-2 seroprevalence worldwide: a systematic review and meta-analisis. Clin Micro and Infection. Published Oct 23, 2020. DOI: https://doi.org/10.1016/j.cmi.2020.10.020

2. Acurio D, Gómez A, Orellana D, Vega B, Charry R, et al. (2020) Estudio de seroepidemiología de la infección por SARS COV-2 en el cantón Cuenca. https://ucuenca.edu.ec.

3. Álava N, Ávila M, Castro J. et al. (2021) Seroprevalencia de la COVID-19, factores de riesgo y protocolos de bioseguridad en el personal de salud de la ciudad de Jipijapa provincia de Manabí, 
Ecuador. Doi: $10.23857 / p c . v 6 i 7.2825$

4. Sidiq Z, Hanif M, Dwivedi K, et al. (2020). Benefits and limitations of serological assays in COVID19 infection. Indian J Tuberc. Dec; 67(4): S163-S166. Doi: 10.1016/j.ijtb.2020.07.034

5. Deeks JJ, Dinnes J, Takwoingi Y, Davenport C, Spijker R, Taylor-Phillips S, Adriano A, Beese S, Dretzke J, Ferrante di Ruffano L, Harris IM, Price MJ, Dittrich S, Emperador D, Hooft L, Leeflang MMG, Van den Bruel A. Antibody tests for identification of current and past infection with SARSCoV-2. Cochrane Database of Systematic Reviews 2020, Issue 6. Art. No.: CD013652. Doi: 10.1002/14651858.CD013652

6. Huang C, Wang Y, Li X, et al. (2020) Clinical features of patients infected with 2019 novel coronavirus in Wuhan, China. Lancet. 2020; 395:497-506 